\title{
Poverty, Food Insecurity, HIV Vulnerability and the Impacts of AIDS in sub-Saharan Africa
}

\author{
Stuart Gillespie*
}

\begin{abstract}
Throughout this decade, the prevailing narrative on the links between socioeconomic status and HIV portrays poor individuals and households as being more vulnerable to HIV infection, ${ }^{1}$ and least able to cope with the ensuing impacts of AIDS-related disease and death. While early stages of the epidemic in the 1980s and early 1990s were driven by 'mobile men with money', AIDS is now conventionally perceived as a disease of poverty. But is this too simplistic?
\end{abstract}

This brief overview aims to review the current evidence on the upstream and downstream links between poverty, food insecurity, HIV vulnerability and the impacts of AIDS. The first section focuses on the upstream - that is, whether, and through what pathways, poverty puts people at greater risk of being exposed to the virus. This is followed by an examination of what is known about the downstream (or post-infection) side - how AIDSrelated disease, and premature mortality exacerbate or precipitate poverty.

While it is hard to decide where to draw the line when discussing vulnerability and impacts - given the interconnectedness of resources, livelihood strategies and the multidimensional responses to shocks and stresses - the focus is very much on poverty, inequality and food insecurity. Geographically, the predominant concern is with eastern and southern Africa, where the coexistence of (and the interactions between) poverty, food insecurity, HIV and AIDS are more widespread and more severe than anywhere else.

\section{Does poverty increase vulnerability to HIV??} It's wrong to think of AIDS as a disease of poverty, AIDS is a disease of inequality; it's not exactly the same thing. It is a disease of inequality between men and women. Gender inequality is a major driver of this epidemic in many countries, or economic inequality... When you do the same exercise for any other health issue in the same countries it's the poor that are the most affected and that is another challenge also for the theologians of development practice ... but we know of course that the downstream impact is much greater among the poor, much greater ... (Piot 2008)

\subsection{Do poorer countries have higher HIV prevalences?}

At the country level there is a weak positive relationship between national wealth and HIV prevalence across countries in sub-Saharan Africa, where higher prevalence is seen in the wealthier countries of southern Africa (Gillespie et al. 2007) Strong urban-rural economic linkages, good transport links and high professional mobility may translate into both higher incomes and higher HIV incidence. National poverty rates, on the other hand, do not show a strong association with HIV prevalence (AIDS is hyperendemic only in Southern Africa, which, in general, is wealthier than East Africa). But there is a clear and significant pattern of association between income inequality and HIV prevalence across countries - countries with greater inequality have higher HIV prevalence (Gillespie et al. 2007). 


\subsection{Are individuals from poor households more at risk of HIV infection?}

Examining HIV vulnerability at the level of households and communities, we find that evidence is mixed (Wojciki 2005; Nyindo 2005). While early studies tended to find positive correlations between household economic resources, education and HIV infection (e.g. Ainsworth and Semali 1998), as the epidemic has progressed, it has increasingly been assumed that this relationship is changing. In most countries, relatively rich and better educated men and women have higher rates of partner change because they have greater personal autonomy and spatial mobility (e.g. Gregson et al. 2006). Although the richer and better educated are likely to have better access to reproductive health care, condom use is generally low in Africa and other parts of the developing world. Pre-existing sexual behaviour patterns (from 'pre-HIV' times) therefore make the richer and the better educated more vulnerable to HIV infection, especially in the early stages of the epidemic, when information about the virus and how to protect oneself is usually low (Anderson et al. 1991). At a later stage, however, it has been argued that individuals with higher socioeconomic status tend to adopt safer sexual practices, once the effects of AIDS-related morbidity and mortality become more apparent (de Walque et al. 2005).

Another postulated dynamic is that poverty (possibly itself fuelled by AIDS) is placing individuals from poor households at greater risk of exposure to HIV via the economically driven adoption of risky behaviours. Poverty and food insecurity are thought to increase sexual risk taking, particularly among women who may engage in transactional sex to procure food for themselves and their children. Women's economic dependence on their partners may also make it difficult for them to insist on safer sex (e.g. condom use). Several ethnographic studies do suggest that material poverty has increased the incidence of transactional sex (e.g. Byron et al. 2006 in Zambia, and Bryceson and Fonseca 2006 in Malawi).

Examining nationally representative Demographic and Health Survey (DHS) data from eight countries in subSaharan Africa, Mishra et al. (2007), however, find a positive association between an asset-based wealth index and HIV status. This relationship was stronger for women, and it was clear that HIV prevalence was generally lower among the poorest individuals in these countries. This is partly accounted for by an association of wealth with other underlying factors. Wealthier ${ }^{3}$ individuals tend to live in urban areas where HIV is more prevalent, they tend to be more mobile, more likely to have multiple partners, more likely to engage in sex with non-regular partners, and they live longer - all factors that may present greater lifetime HIV risks. But, on the other hand, they tend to be better educated, with better knowledge of HIV prevention methods, and are more likely to use condoms - factors that reduce their risk relative to poorer individuals. Controlling for these associations, however, does not reverse the conclusion - there is no apparent association between low wealth status and HIV.

Such cross-sectional studies are, however, unable to distinguish between the effect of economic status on HIV infection and the reverse, i.e. the effect of HIV infection on economic status. And they are unable to control for the fact that individuals from richer households may survive longer with HIV, and are thus more likely to be present in the population to be tested, thereby increasing HIV prevalence rates. Such limitations can be overcome by using prospective cohorts to track HIV incidence. Three recent studies shed some light here - one from Zimbabwe suggests incidence peaks in poorer groups (Lopman et al. 2007), one in KwaZulu Natal, South Africa, suggests it peaks in the middle asset-wealth class (Bärnighausen et al. 2007), and one in Limpopo, South Africa, finds no relation between HIV incidence and wealth (Hargreaves et al. 2007).

Links between socioeconomic conditions and HIV risk and vulnerability are complex. A major analytical challenge is to define the causal pathways operating from distal socioeconomic factors to proximal individual behaviours and ultimately physiological factors. Different socioeconomic factors may affect health at different times in the life course, operating at different levels (e.g. individual, household, and neighbourhood) and through different causal pathways (Gillespie et al. 2007). There are several key mediating factors, as follows:

- First, gender is front and central to any discussion of HIV and poverty. HIV infection rates in young women are usually the highest of any subgroup in the most affected countries (UNAIDS 2007). Gender inequity shapes power relations, sexual relations and thus risk. Women are biologically at greater risk of HIV infection than men - they are also more likely to have other sexually transmitted 
diseases (which can quadruple the risk of HIV transmission), and less likely to seek treatment (Galvin and Cohen 2004). Socioculturally, women's relative powerlessness increases risk. Women are less likely to negotiate condom use, inside or outside of marriage, and more at risk from sexual practices such as dry sex. The male partner is often considerably older than the female, further unbalancing the power differential, and increasing risk of sexual coercion. Economic asymmetries within a couple are reinforced by various contextual factors, such as family and peer pressures, social and economic institutions and pervasive and deeply entrenched gender-based inequalities. One recent study in Kenya, for example, found - conditional on a set of individual and community characteristics gender economic inequality between young women and adult men to be significantly correlated with individual's HIV-positive status (Beegle and Ozler 2007). Other evidence points to significant positive associations between larger age differences between partners, value of economic transactions and unsafe sexual behaviours (e.g. Luke 2005). In Botswana and Swaziland, food insufficiency among women was found to be significantly associated with inconsistent condom use with a non-primary partner, sex exchange, intergenerational sexual relationships and lack of control in sexual relationships (Weiser et al. 2007). Sex workers in Kenya are more likely to have unprotected sex when struggling with unexpected income shocks (Robinson and Yeh 2008).

- Second, the link between mobility and the spread of HIV is determined by the structure of the migration process, the conditions under which it occurs, including poverty, exploitation, separation from families and partners, and separation from the sociocultural norms that guide behaviours within communities (Crush et al. 2006). Mobility can increase vulnerability to high risk sexual behaviour as migrants' multi-local social networks create opportunities for sexual networking. In eastern and southern Africa, plantations and related agricultural industries are often associated with situations of significant risk (Byron et al. 2006). More mobile people are also harder to reach for preventive care or treatment services (Bärnighausen et al. 2007).

- Third, social cohesion and social capital are other important conditioning factors (Barnett and
Whiteside 2006). A higher HIV risk was found to be significantly associated with community-level structural factors (including easier access to a trading centre, higher proportions of short-term residents, and lower levels of social capital) in a study in Limpopo, South Africa (Pronyk et al. 2008, in press). Among men, higher HIV prevalence was also seen among communities with easier access to a local mine, a higher density and activity of local bars, a higher number of sex workers per village and lower proportions of out-migrants. More research is needed on social cohesion and HIV risk.

- Fourth, nutrition is the pivotal interface between food security and health security. An individual's susceptibility to any disease depends on the strength of the immune system, which among other factors is affected by nutrition, stress, and the presence of other infections and parasites. Worms cause malnutrition through malabsorption and intestinal bleeding, and they weaken the immune response. Infectious and parasitic diseases and malnutrition thus create an environment of enhanced risk (Stillwaggon 2006). Malnutrition, particularly involving vitamin A-deficiency, is also associated with an increased risk of genital ulcers and cervical HSV (herpes simplex virus) shedding (Mostad et al. 2000), which in turn has been found to increase the risk of HIV transmission (Galvin and Cohen 2004).

\section{How does AIDS impact poverty and food insecurity? ${ }^{4}$}

Starting with the individual who has become infected with HIV, we continue to track the path of the virus, examining impacts of AIDS-related morbidity and mortality on poverty and food security - moving upward and outward from individuals, through households and communities, up to national levels.

\subsection{Impacts on individuals}

In addition to their greater risk of being infected with HIV (described above), the extra burden of care brought on by AIDS is falling on the shoulders of millions of women, with implications for their health, nutritional wellbeing, psychosocial status, and those of their dependent children (Gillespie and Kadiyala 2005). Of the numerous types of individual impact, the violation of women's rights to property is one of the most hidden and most serious. $A$ 
recently widowed woman may be expected to leave her husband's village after his death, and she may lose control over land and other assets that they had been jointly using as a family. In a Zambian study, 1-3 years following the death of their husbands, widowheaded households, on average, had control of 35 per cent less land than prior to their husband's death (Chapoto et al. 2007).

Another major individual-level impact of HIV-related morbidity is on nutritional status. Nutrition and immunity in $\mathrm{HIV}$-positive individuals can interact in two ways. First, HIV-induced immune impairment and heightened subsequent risk of opportunistic infection can worsen nutritional status. HIV infection often leads to nutritional deficiencies through decreased food intake, malabsorption and increased utilisation and excretion of nutrients, which in turn can hasten death (Semba and Tang 1999). Second, nutritional status modulates the immunological response to HIV infection, affecting the overall clinical outcome. Four decades ago, research started to shed light on this 'malnutrition-infection complex' with the term 'NAIDS' (Nutritionally Acquired Immune Deficiency Syndrome) being coined (Scrimshaw et al. 1968). Individuals living with HIV require 10 per cent extra calories if they are asymptomatic, and 20-30 per cent extra if they are symptomatic (WHO 2003). Nutritional impacts of HIV infection at the individual level will have implications for whole households, as discussed later, especially where income is dependent on manual labour productivity.

How is child nutrition affected? Children may be affected if one of their parents (or another adult in the household) is living with HIV or has died of AIDS. Studies have shown effects of maternal illness on child nutrition and health whether or not the child is infected with HIV (Chatterjee et al. 2007; Newell et al. 2004).

Evidence of differential nutritional impacts on orphaned children is mixed. A recent regional study in Africa found that orphans were not more underweight than other children, after adjusting for confounding (Rivers et al. 2008). Other studies show similar findings (e.g. Taha et al. 2000 in Malawi). Yet, in a Tanzanian study, orphaned children were more likely to be stunted (Ainsworth and Semali 2000), with the most severely affected being children in the poorest households, those with uneducated parents and with least access to healthcare.
The type of orphanhood appears significant. In Tanzania, Ainsworth and Semali (2000) found maternal orphans to be at significantly greater nutritional risk than paternal orphans (the impact of maternal loss was severe regardless of household assets, while the impact on paternal loss was felt only among poor households). A decade ago, Ntozi et al. (1999) found that surviving fathers in Uganda provided more care than mothers because, they suggested, the fathers had greater means, and the husband's relatives often denied widows the opportunity to look after the orphans.

Paternal orphans tend to live in poorer households than maternal orphans, double orphans or nonorphans, according to analysis of DHS data (Case et al. 2003) and a study in Zimbabue (Nyamukapa et al. 2003). Households containing either maternal or double orphans were not poorer than those of nonorphans.

The regional study by Rivers et al. 2008 also found that while households could manage to absorb one orphan without being impacted significantly, they appeared unable to take on more orphans without affecting livelihood activities. As mortality rates increase and the population of orphans continues to rise, more and more households will be faced with the decision of whether to foster more than one orphan at a time.

\subsection{Socioeconomic impacts of AIDS on households and communities}

Since the threat that AIDS epidemics pose for food security was recognised in the late 1980s (Gillespie 1989), many studies in sub-Saharan Africa have since shown that subsistence farmers are vulnerable to the impacts of AIDS because the disease reduces the resources that households can devote to agriculture (recent reviews include Gillespie 2006 and Edström and Samuels 2007). Labour loss occurs not only as a result of sickness and premature adult death, but also as a result of its reallocation to nurse the ill, while working capital and income is siphoned off to pay for mounting medical bills. The degree and type of vulnerability depend on the characteristics of families, livelihoods and farming systems.

AIDS has also affected commercial agriculture, although companies have become adept at shifting the costs of employee ill-health back to the employees themselves in a variety of ways (Rosen and 
Simon 2002). Agricultural extension is being hit hard too, by the sickness and death of extension agents who are at particular risk because of their mobility.

Spanning out, as rural communities with high HIV prevalence face increased labour shortages, widespread reductions in household incomes and increased cash constraints may also depress demand for labour, leading to wage declines that hit poor households not directly affected by AIDS (Dorward and Mwale 2006). In one of the few studies to quantitatively examine community-level AIDS impacts, Jayne et al. (2006) found modest effects on land area cultivated in Zambia, using nationally representative longitudinal survey data. In another ethnographic study in Zambia, Drinkwater et al. (2006) restudied two communities, one peri-urban and one rural, 12 years after the original study, using household clusters as the unit of analysis. The position of the person who is chronically ill or has died was found to be a key determinant of the resilience of the cluster, with primary producer deaths having the most serious consequences. However, prime-aged mortality tended to be more concentrated among 'secondary producers', i.e. younger adults who would in future be expected to become primary producers. This suggests the full impact of AIDS on agriculture should be viewed over a relatively long - even inter-generational - period of time.

In Rwanda, Donovan and Bailey (2006) found the relatively small mortality impacts on production may primarily be a reflection that pre-death measurements occurred during the illness period, when the household was already adjusting to AIDSrelated illness. The importance of looking at how households respond to illness (not just death) is borne out by a study of tea estate workers in Kenya that rigorously quantified the impact of AIDS-related illness on individual labour productivity during disease progression (Fox et al. 2004). After adjusting for confounding, tea pluckers who stopped working because of AIDS-related causes were found to have earned 16 per cent less in their second year before termination and 18 per cent less in the year before termination

It is important to stress that impacts of AIDS on agriculture (and indeed other sources of livelihood) are not one-time events - they are processes, often hidden and slow-burning but potentially very destructive. AIDS can exert its effects over a relatively long period of time while rendering other stresses/shocks both more likely and more severe in their effects. Following a shock to household income, households in Malawi affected by AIDS were found to take up to 18 months to stabilise, with a new equilibrium income that was about half the pre-shock income levels (Masanjala 2006). Similar findings had been reported earlier in Kenya (Yamano and Jayne 2004). Such limited resilience is likely to increase vulnerability to other shocks. Studies are under way, for example, to investigate the impact of soaring food prices on households struggling to deal with AIDS, but the additional effects - where households are net buyers of food - are likely to be severe.

Where households are not subject to additional stresses such as drought, and when viewed over a relatively short period (e.g. a couple of years), traditional responses can mitigate the worst effects of AIDS. However, complex factors determine the success of these strategies. These include the sex, age, and position in the household of the ill/deceased person, the household's socioeconomic status, the type and degree of labour demand in the production system, the availability of labour support to affected households, other livelihood opportunities, available natural resources, the availability of formal and informal sources of support including credit and inter-household transfers, the length of time that the epidemic has been impacting upon the rural economy, and the existence of concurrent shocks such as drought or commodity price collapses (de Waal et al. 2005; Gillespie and Kadiyala 2005).

The hypothesis that AIDS could contribute to famine was first floated during the southern African drought of 2002-3, when the extent and depth of hunger surprised many observers who had expected that peace and economic growth would have banished food insecurity. The 'new variant famine' hypothesis (de Waal and Whiteside 2003) posited that AIDS contributed to the crisis in several ways, most notably by reducing the resilience of affected households and limiting their ability to cope with the crisis. As detailed evidence became available, the hypothesis was refined (de Waal 2007). The role of AIDS in altering livelihood patterns and increasing householdlevel vulnerability to hunger was identified as significant, especially when combined with other shocks such as drought or market failure. Some evidence exists for AIDS as a factor in exacerbating 
child malnutrition during crises. No data have been collected to test whether AIDS contributes to higher mortality during periods of acute food insecurity.

\section{Conclusion}

While the poor are undoubtedly hit harder by the downstream impacts of AIDS, in a variety of ways, their chances of being exposed to HIV in the first place are not necessarily greater than wealthier individuals or households. There is strong evidence that socioeconomic and gender inequalities condition the spread of HIV, while AIDS-related disease and death increases these inequalities $-a$ potentially vicious cycle.

Globally, Africa is the poorest continent with by far the most serious AIDS epidemics. But it is in southern Africa where socioeconomic and gender inequalities, and population mobility, are most extreme, and where AIDS is hyperendemic (onethird of all people living with HIV reside in southern Africa). Poverty per se may not be the most important factor conditioning the risk of being exposed to HIV - but without question, it is the poor in these countries, and especially poor women, who are struggling the most with the subsequent impacts of AIDS. If you are a person living with HIV and you are poor, it will be harder for you to sustainably access antiretroviral therapy; it will be harder to find and pay for treatment for opportunistic infections which (if you are malnourished) will usually be more severe, and it will be harder to ensure any medical treatment is complemented by a diverse and reliable diet. At the household level, poverty will worsen the impacts of other livelihood stresses and shocks, and close down options for effectively responding. At the end of the line, it is women and children who are the most vulnerable.

What does this imply for the AIDS response? First, in terms of stemming the flow of new infections, approaches to HIV prevention clearly need to cut across all socioeconomic strata of society and they need to be tailored to the specific drivers of transmission within different groups - with particular attention to the vulnerabilities faced by youth and women, and to the dynamic and contextual nature of the relationship between socioeconomic status and HIV. Second, to better respond to the downstream or post-infection impacts of AIDS-related disease and death, mitigation needs to focus on increasing resilience of poor and vulnerable households through enhancing local capacity and providing options and incentives for safe livelihood strategies. This in turn needs to be complemented by effective state-led systems of social protection, underpinned by equitable macroeconomic growth policies, gender-progressive legislation and implementation.

\section{Notes}

* The author is very grateful to Alex de Waal and Anna Paden for their contributions to this article.

1 For example: 'Across the continent, poverty structures not only the contours of the pandemic but also the outcome once an individual is infected with HIV. Thus, until poverty is reduced, there will be little progress with either reducing transmission of the virus or creating an enhanced capacity to cope with its socioeconomic consequences' (Freedman and Poku 2005).

2 This section draws considerably on a recent review by Gillespie et al. (2007).

3 Most studies focus on relative poverty and relative wealth in the context of generalised chronic

poverty. In fact, it is only the highest one or two quintiles (or possibly three in middle-income southern African countries) that can be thought of as representing the non-poor, using the standard poverty line definitions, or the \$1- or $\$ 2$-a-day measures adopted for the purpose of global comparison. Comparisons are thus between 'wealthier' and 'poorer' groups.

4 A detailed discussion of macroeconomic impacts of AIDS is beyond the scope of this article, so the focus here is on individual, household and community-level impacts. 


\section{References}

Ainsworth, M. and Semali, I. (2000) The Impact of Adult Deaths on Children's Health in Northwestern Tanzania, World Bank Paper, Washington DC: World Bank Development Research Group Ainsworth, M. and Semali, I. (1998) 'Who is Most Likely to Die of AIDS? Socioeconomic Correlates of Adult Deaths in Kagera Region, Tanzania', in M. Ainsworth, L. Fransen and M. Over (eds), Confronting AIDS: Evidence from the Developing World, Brussels: European Commission

Anderson, R.M.; May, R.M.; Boily, M.C.; Garnett, G.P. and Rowley, J.T. (1991) 'The Spread of HIV-1 in Africa: Sexual Contact Patterns and the Predicted Demographic Impact of AIDS', Nature 352.6336: 581-9

Barnett, T. and Whiteside, A. (2006) AIDS in the 21st Century: Disease and Globalization, New York: Palgrave Press

Bärnighausen, T.; Hosegood, V.; Timaeus, I.M. and Newell, M.L. (2007) 'The Socioeconomic Determinants of HIV Incidence: Evidence from a Longitudinal, Population-Based Study in Rural South Africa', AIDS 21 suppl. 7: S29-38

Beegle, K. and Ozler, B. (2007) Young Women, Rich(er) Men, and the Spread of HIV, Washington DC: World Bank

Bryceson, D. and Fonseca, J. (2006) 'An Enduring or Dying Peasantry: Interactive Impact of Famine and HIV/AIDS in Rural Malawi', in Stuart Gillespie (ed.), AIDS, Poverty, and Hunger: Challenges and Responses, Washington DC: International Food Policy Research Institute (IFPRI)

Byron, E.; Gillespie, S.R. and Hamazakaza, P. (2006) 'Local Perceptions of Risk and HIV Prevention in Southern Zambia', RENEWAL Working Paper, www.ifpri.org/renewal (accessed 13 June 2008)

Case, A.; Hosegood, V. and Lund, F. (2003) 'The Reach of the South African Child Support Grant: Evidence from Kwa-Zulu Natal', unpublished

Chapoto, A.; Jayne, T.S. and Mason, N. (2007) Security of Widows' Access to Land in the Era of HIV/AIDS: Panel Survey Evidence from Zambia, Ministry of Agriculture and Cooperatives, Agricultural Consultative Forum, Michigan State University and Lusaka, Zambia, Policy Synthesis, Food Security Research Project 22, wwwaec.msu.edu/agecon/fs2/zambia/index.htm (accessed 7 September 2007)

Chatterjee, A.; Bosch, R.; Hunter, D.; Fataki, M.; Msamanga, G. and Fawzi, W. (2007) 'Maternal Disease Stage and Child Undernutrition in Relation to Mortality among Children Born to HIV-infected Women in Tanzania', Journal of Acquired Immune Deficiency Syndromes 46.5: 599-606

Crush, J.; Frayne, B. and Grant, M. (2006) 'Linking Migration, HIV/AIDS and Urban Food Security in Southern and Eastern Africa', RENEWAL Working Paper, Washington DC: International Food Policy Research Institute (IFPRI)

de Waal, A. (2007) AIDS and Power, London: Zed Books

de Waal, A. and Whiteside, A. (2003) 'New Variant Famine: AIDS and Food Crisis in Southern Africa', The Lancet 362.9391: 1234-7

de Waal, A.; Tumushabe, J.; Mamdani, M. and Kilama B. (2005) 'HIV/AIDS and Changing Vulnerability to Crisis in Tanzania: Implications for Food Security and Poverty Reduction', presented at HIV/AIDS and Food and Nutrition Security meeting, 14-16 April, Durban, South Africa

de Walque, D.; Nakiyingi-Miiro, J.S.; Busingye, J. and Whitworth, J.A. (2005) 'Changing Association Between Schooling Levels and HIV-1 Infection Over 11 Years in a Rural Population Cohort in South-West Uganda', Tropical Medicine and International Health 10.10: 993-1001

Donovan, C. and Bailey, L. (2006) 'Understanding Ruandan Agricultural Households' Strategies to Deal with Prime Age IIIness and Death: A Propensity Score Matching Approach', in Stuart R. Gillespie (ed.), AIDS, Poverty, and Hunger: Challenges and Responses, Washington DC: International Food Policy Research Institute (IFPRI)

Dorward, A. and Mwale, I. (2006) 'Labour Market and Wage Impacts of HIV/AIDS in Rural Malawi', in Stuart R. Gillespie (ed.), AIDS, Poverty, and Hunger: Challenges and Responses, Washington DC: International Food Policy Research Institute (IFPRI)

Drinkwater, M.; McEwan, M. and Samuels, F. (2006) 'The Effects of HIV/AIDS on Agricultural Production Systems in Zambia: A Restudy 1993-2005', analytical report, CARE-RENEWAL study, www.ifpri.org/renewal/pdf/Zambia_AR.pdf (accessed 10 June 2008)

Edström, J. and Samuels, F. (2007) HIV, Nutrition, Food and Livelihoods in Sub-Saharan Africa: Evidence, Debates and Reflections for Guidance, www.livelihoods.org/info/docs/DFID\%20on\%20AI DS,\%20Food\%20\%20and\%20Livelihoods.pdf (accessed 30 October 2007)

Fox, M.P.; Rosen, S.; MacLeod, W.B.; Wasunna, M.; Bii, M.; Foglia, G. and Simon, J.L. (2004) 'The Impact of 
HIV/AIDS on Labour Productivity in Kenya', Tropical Medicine and International Health 9.3: 318-24

Freedman, J. and Poku, N. (2005) 'The Socioeconomic Context of Africa's Vulnerability to HIV/AIDS', Review of International Studies 31.4: 665-86

Galvin, S.R. and Cohen, M.S. (2004) 'The Role of Sexually Transmitted Diseases in HIV Transmission', Nature Reviews. Microbiology 2.1: 33-42

Gillespie, S.R. (2006) AIDS, Poverty, and Hunger: Challenges and Responses, Washington DC: International Food Policy Research Institute (IFPRI)

Gillespie, S.R. (1989) 'Potential Impact of AIDS on Farming Systems: A Case Study from Rwanda', Land Use Policy 6.4: 301-12

Gillespie, S.R. and Kadiyala, S. (2005) HIV/AIDS and Food and Nutrition Security: From Evidence to Action, Food Policy Review 7, Washington DC: International Food Policy Research Institute (IFPRI)

Gillespie, S.R.; Kadiyala, S. and Greener, R. (2007) 'Is Poverty or Wealth Driving HIV Transmission?', AIDS 21 suppl. 7: S5-16

Gregson, S.; Garnett, G.P.; Nyamukapa, C.A.; Hallett, T.B.; Lewis, J.J.; Mason, P.R.; Chandiwana, S.K. and Anderson, R.M. (2006) 'HIV Decline Associated with Behaviour Change in Eastern Zimbabwe', Science 311.5761: 664-6

Hargreaves, J.R.; Bonell, C.P.; Morison, L.A.; Kim, J.C.; Phetla, G.; Porter, J.D.H.; Watts, C. and Pronyk, P.J. (2007) 'Explaining Continued High HIV Prevalence in South Africa: Socioeconomic Factors, HIV Incidence and Sexual Behaviour Change Among a Rural Cohort, 2001-2004', AIDS 21 suppl. 7: S39-48

Jayne, T.; Chapoto, A.; Byron, E.; Ndiyoi, M.; Hamazakaza, P.; Kadiyala, S. and Gillespie, S. (2006) 'Community-Level Impacts of AIDSRelated Mortality: Panel Survey Evidence from Zambia', Review of Agricultural Economics 28.3: $440-57$

Lopman, B.; Lewis, J.; Nyamukapa, C.; Mushati, P.; Chandiwana, S. and Gregson, S. (2007) 'HIV Incidence and Poverty in Manicaland, Zimbabue: Is HIV Becoming a Disease of the Poor?', AIDS 21 suppl. 7: S57-66

Luke, N. (2005) 'Confronting the "Sugar Daddy" Stereotype: Age and Economic Asymmetries and Risky Sexual Behaviour in Urban Kenya', International Family Planning Perspectives 31.1: 6-14

Masanjala, W.H. (2006) 'HIV/AIDS, Household Expenditure and Consumption Dynamics in Malawi', in Stuart R. Gillespie (ed.), AIDS, Poverty, and Hunger: Challenges and Responses, Washington
DC: International Food Policy Research Institute (IFPRI)

Mishra, V.; Assche, S.B.; Greener, R.; Vaessen, M.; Hong, R.; Ghys, P.D.; Boerma, J.T.; Van Assche, A.; Khan, S. and Rutstein, S. (2007) 'HIV Infection does not Disproportionately Affect the Poorer in Sub-Saharan Africa', AIDS 21 suppl. 7: S17-29

Mostad, S.B.; Kreiss, J.K.; Ryncarz, A.J.; Mandaliya, K.; Choha, N.B.; Ndinya-Achola, J.; Bwayo, J.J. and Corey L. (2000) 'Cervical Shedding of Herpes Simplex Virus in Human Immunodeficiency Virusinfected Women: Effects of Hormonal Contraception, Pregnancy, and Vitamin A Deficiency', Journal of Acquired Immune Deficiency Syndrome 181.1: 58-63

Newell, M.L.; Coovadia, H.; Cortina-Borja, M.; Rollins, N.; Gaillard, P. and Dabis, F. (2004) 'Mortality of Infected and Uninfected Infants Born to HIV infected Mothers in Africa: A Pooled Analysis', The Lancet 364.9441: 1236-43

Ntozi, J.P.M.; Ahimbisibue, F.E.; O’Dwee, J.; Ayiga, N. and Okurut, F. (1999) 'Orphan Care: The Role of the Extended Family in Northern Uganda', Health Transition Review 8: 225-36

Nyamukapa, C.A.; Foster, G. and Gregson, S. (2003) 'Orphans' Household Circumstances and Access to Education in a Maturing HIV Epidemic in Eastern Zimbabwe', Journal of Social Development in Africa 18.2: 7-32

Nyindo, M. (2005) 'Complementary Factors Contributing to the Rapid Spread of HIV-I in SubSaharan Africa: A Review', East African Medical Journal 82.1: 40-6

Piot, P. (2008) 'AIDS: Exceptionalism Revisited', lecture at London School of Economics, 15 May

Pronyk, P.M.; Morison, L.A.; Euripodou, R.; Phetla, G.; Hargreaves, J.R.; Kim, J.C., et al. (2008) 'The Role of Structural Factors in Explaining Variations in Community HIV Prevalence: A Study in Rural South Africa', Sexually Transmitted Infections, (in press)

Rivers, J.; Mason, J.; Silvestre, E.; Gillespie, S.; Mahy, M. and Monasch, R. (2008) 'Impact of Orphanhood on Underweight Prevalence in Sub-Saharan Africa', Food and Nutrition Bulletin 29.1: 32-42

Robinson, J. and Yeh, E. (2008) 'Transactional Sex as a Response to Risk in Western Kenya', unpublished paper, University of California and McKinsey and Co.

Rosen, S. and Simon, J.L. (2002) Shifting the Burden of HIV/AIDS, www.info.worldbank.org/etools/ library/latestversion. asp?57496.html (accessed 7 May 2008) 
Scrimshaw, N.; Taylor, C. and Gordon, J. (1968) Interactions of Nutrition and Infection, Geneva: World Health Organization (WHO)

Semba, R.D. and Tang, A.M. (1999) 'Micronutrients and the Pathogenesis of Human Immunodeficiency Virus Infection', British Journal of Nutrition 81.3: 181-9

Stillwaggon, E. (2006) 'The Ecology of Poverty, Nutrition, Parasites and Vulnerability to HIV/AIDS', in Stuart R. Gillespie (ed.), AIDS, Poverty, and Hunger: Challenges and Responses, Washington DC: International Food Policy Research Institute (IFPRI)

Taha, T.E.; Graham, S.M.; Kumwenda, N.I.; Broadhead, R.L.; Hoover, D.R.; Markakis, D.; Hoeven, L.V.; Liomba, G.N.; Chiphangwi, J.D. and Miotti, P.G. (2000) 'Morbidity among Human Immunodeficiency Virus-1-infected and -uninfected African Children', Pediatrics 106.6: E77

UNAIDS (Joint United Nations Programme on HIV/AIDS) (2007) Report on the Global AIDS Epidemic, Geneva: UNAIDS
Weiser, S.D.; Leiter, K.; Bangsberg, D.R.; Butler, M.L.; Percy-de Korte, F; Hlanze, Z;; Phaladze, N.; lacopino, V. and Heisler, M. (2007) 'Food Insufficiency is Associated with High-Risk Sexual Behaviour among Women in Botswana and Swaziland', PLoS Medicine 4.10: e260

WHO (World Health Organization) (2003) Nutrient Requirements for People Living with HIV/AIDS: Report of a Technical Consultation, 13-15 May, Geneva

Wojciki, J.M. (2005) 'Socioeconomic Status as a Risk Factor for HIV Infection in Women in East, Central and Southern Africa: A Systematic Review', Journal of Biosocial Science 37.1: 1-36 Yamano, T. and Jayne, T.S. (2004) 'Measuring the Impacts of Working-Age Adult Mortality on Small-Scale Farm Households in Kenya', World Development 32.1: 91-119 